\title{
A CONSTRUÇÃO IDENTITÁRIA DOS ADOLESCENTES POBRES DE PERIFERIA NA ERA DA SOCIEDADE DE CONSUMO E DA INDÚSTRIA CULTURAL
}

\author{
Angela Maria Pires Caniato* \\ Mônica Salci Capelasso** \\ Naiara Valdelaine Balduino***
}

\begin{abstract}
Resumo: O presente trabalho é decorrente do Projeto de Pesquisa Intervenção "Phenix - a ousadia do renascimento do indivíduo-sujeito - fase IV", vinculado a Universidade Estadual de Maringá. As teorizações aqui realizadas partiram de encontros realizados entre graduandos e pós-graduandos de psicologia com adolescentes pauperizados de uma escola pública localizada na periferia de MaringáPR, cujo foco foi propiciar uma reflexão crítica acerca do cotidiano desses adolescentes a partir de Psicanálise e de pressupostos da Teoria Crítica de Adorno. A princípio serão apresentadas nesse trabalho algumas considerações sobre os processos de identificação, adesão e reprodução de discursos totalizantes relacionados a ideias meritocráticas e patriarcalistas que foram discutidas com os adolescentes, com o intuito de desmistificar alguns modelos pré-formatados de família, de homem e de mulher impostos na sociedade contemporânea. Na sequência, serão realizadas breves considerações sobre as especificidades do adolescer dentro de um contexto pauperizado e significativamente marcado pelos imperativos do consumo, via indústria cultural.
\end{abstract}

Palavras-chave: identidade; adolescentes pobres, consumo; indústria cultural.

Abstract: The current paper is the result from the research project and Intervention "'Phenix'- the bold rebirth of the individual subject in phase IV" linked to the State University of Maringa. The theories developed here are based on the meetings executed by, the undergraduate and graduate students of the Psychology program, and underprivileged adolescents from a public school in the suburbs in Maringa-PR. The objective of those meetings was to stimulate critical reflection of the adolescents on their everyday life through Psychoanalysis and the assumptions of the Critical Theory of Adorno. Initially, it will be presented some reflections over the process of the identification, adherence, and reproduction of the totalitarian discourse related to meritocratic and patriarchal ideas that were discussed with the adolescents. The objective of that debate was to demystify some of the preestablished patterns of family, man and woman imposed in contemporary society. It will be also presented some considerations about the specificities of the process of becoming an adolescent in an underprivileged context which is substantially characterized by consumerism through culture industry.

Keywords: identity; poor adolescents, consumerism; cultural industry.

\footnotetext{
" Psicóloga pela Pontifícia Universidade Católica do Rio de Janeiro (1968), Mestre em Psicologia Social pela Pontifícia Universidade Católica de São Paulo (1986) e Doutora em Psicologia pela Universidade de São Paulo (1995). Professora do Programa de Pós-Graduação em Psicologia da Universidade Estadual de Maringá UEM e Psicóloga Clínica. E-mail: angelacaniato@gmail.com

** Psicóloga pela Universidade Estadual de Maringá (2014), Especialista em Psicanálise Clínica pela Escola de Psicoterapia Psicanalítica de Maringá (2016), Mestranda no Programa de Pós-Graduação em Psicologia pela Universidade Estadual de Maringá. Bolsista da Fundação Araucária e Psicóloga Clínica. E-mail: monicapelasso@gmail.com

**** Psicóloga pela Universidade Estadual de Maringá (2016), Mestranda no Programa de Pós-Graduação em Psicologia pela Universidade Estadual de Maringá. Bolsista da CAPES e Psicóloga Clínica. E-mail: naiarabalduino@gmail.com
}

CANIATO, Angela Maria Pires; CAPELASSO, Mônica Salci; BALDUINO, Naiara Valdelaine. A construção identitária dos adolescentes pobres de periferia na era da sociedade de consumo e da indústria cultural. Revista Sul-Americana de Filosofia e Educação. Número 29: nov./2017-abr./ 2018, p. 19-28. DOI: https://doi.org/10.26512/resafe.v0i29.21003 
Os conceitos teóricos/conceituais que serão analisados neste estudo baseiam-se na reciprocidade dialética entre indivíduo $e$ cultura, a partir das demarcações dos campos da Psicanálise freudiana $e$ da Teoria Crítica da Sociedade de Adorno e Horkheimer. As indagações que aqui serão apresentadas, decorrem de um trabalho desenvolvido com adolescentes pauperizados de uma escola estadual da rede pública de ensino de Maringá/PR. Os encontros foram realizados no primeiro semestre de 2016 pelos discentes da graduação e pós-graduação integrantes do Projeto de Pesquisa Intervenção "Phenix - a ousadia do renascimento do indivíduosujeito - fase IV", vinculado à Universidade Estadual de Maringá.

Esse projeto é coordenado pela professora permanente voluntária Dra. Angela Maria Pires Caniato e, tem como objetivo central possibilitar uma reflexão crítica acerca de questões cotidianas que permeiam a vida dos adolescentes, em especial, as malignidades sociais introjetadas por eles, tais como, de serem perigosos e incapazes, além de violentos $e$ desocupados, etc. Sabemos que esses estigmas passam a nortear as ações cotidianas desses adolescentes, expressando suas "cumplicidades" com esses estereótipos que lhes são socialmente imputados. Dessa forma, compreendemos a importância de trabalhar com esses adolescentes, questões que adentraram o seu cotidiano, a fim de que, por meio da reflexão crítica, eles possam diferenciar essas situações de violência e exclusão social de suas reais identidades. Isso significa dizer, proporcionar espaços de resistência contra as amarras ideológicas da indústria cultural.

A pesquisa intervenção tem servido como escopo metodológico desta prática e viabilizado a construção de espaços de problematização coletiva da realidade psicossocial desses adolescentes. A teoria psicanalítica que se constrói nessa interface com a prática clínica, ganha desdobramentos na aplicação extramuros (ROSA e DOMINGUES, 2010), como é o caso da referida pesquisa intervenção, visto que o desenvolvimento da consciência crítica favoreceria o desvelamento das mentiras manifestas (ideologias) que, de alguma forma, adentram a realidade psíquica dos indivíduos via inconsciente.

Para a análise destes caminhos intrapsíquicos, os conceitos da psicanálise foram a nossa linha condutora, além de serem balizadores metodológicos para a relação transferencial com os adolescentes do projeto, pautada, sobretudo, na inscrição da alteridade com os adolescentes. Já a Teoria Crítica adorniana agrega contribuições no pensar de uma educação para a emancipação humana, no sentido de possibilitar aos adolescentes um vir-a-ser sujeito refletido da história humana, das contradições sociais vigentes e capaz de impedir a repetição da violência, dos preconceitos, da exclusão social e da barbárie que cada vez mais tem se instalado socialmente. O que se espera segundo Adorno (1995), é a prática do "conteúdo positivo, emancipatório, do movimento de ilustração da razão" (ADORNO, 1995, p.12), que não só compreende o presente como histórico, mas rejeita uma direção pré-determinada 
para a história e lhe confere um sentido emancipatório que se constrói na elaboração do passado e no devir do futuro.

A partir dessas questões, traçamos como objetivo deste trabalho apresentar algumas considerações sobre o processo de identificação, adesão e reprodução de discursos totalizantes por adolescentes na contemporaneidade. Esses discursos são geralmente produzidos pelos meios de comunicação de massa e reproduzidos em propagandas direcionadas ao público jovem/adolescente. Para ilustrar esse processo de identificação e internalização de certas ideias universalizantes, apresentaremos alguns relatos produzidos pelos adolescentes da periferia de Maringá que participam das intervenções do Projeto Phenix, bem como teceremos algumas articulações com alguns discursos disseminados pela mídia em forma de propagandas.

$\mathrm{Na}$ contemporaneidade, vivemos imersos em uma sociedade marcada pelo grande fluxo de informações e tecnologias que permitem o 'livre acesso' às mais variadas expressões culturais, políticas, de entretenimento e de consumo. Por que então temos nos deparado cada vez mais com indivíduos apáticos, docilizados e que aderem a discursos hegemônicos $e$ totalitários? Ou mais especificamente, por que muitos adolescentes estariam aderindo com tanta facilidade a esses discursos e reproduzindo-os em sua vida cotidiana? Seriam eles presas fáceis e manipuláveis que consomem e reproduzem passivamente essas ideias? Não se pretende aqui responder toda a complexidade dessas indagações, mas sim tecer algumas considerações acerca dessas questóes em uma tentativa de estabelecer um diálogo que permita vislumbrar algumas facetas sobre o vir a ser adolescente nos cenários da indústria cultural frente a internalização da violência simbólica.

Nos encontros do Projeto Phenix, a mídia televisiva $e$ as propagandas dispositivos de produção $e$ disseminação de discursos totalizantes -, foram temas de discussão em várias intervenções e mobilizaram diferentes compreensões $e$ posicionamentos em relação à função da mídia e os engodos disseminados nas propagandas da contemporaneidade. Havia certa divergência entre os adolescentes quanto a 'potência' massificadora dos meios de comunicação $e$ em relação à adesão a certos discursos sustentados por ideologias e alimentados pelos efeitos da tecnologia e de uma racionalidade técnica.

Por outro lado, os adolescentes apresentaram como ponto de convergência a reprodução constante desses discursos pré-fabricados, como se fossem verdades absolutas $e$ oriundas de sua própria capacidade reflexiva. Além disso, eles não só aderiam a esses discursos, como os utilizavam cotidianamente com seus pares e em diferentes contextos: na escola, com os amigos, com a família e em outros ambientes de socialização. Bem ou mal, todos os adolescentes manifestaram sentir os efeitos ora sutis, ora manifestos dessas narrativas, e não só isso, mas dando adesão a elas e assumindo como próprias.

Os discursos totalizantes a que nos referimos diz respeito à ideias 
generalizadoras pautadas na meritocracia $e$ na superioridade do patriarcado que circunscreve a sociedade brasileira desde o período colonial. Dentro desse modelo de patriarcado, segundo CHAUí, Marilena (2012), o contexto familiar é marcado por uma hierarquia soberana do patriarca, $\mathrm{o}$ qual não reconhece os demais integrantes da família como sujeitos de direitos. Essa ideia de família, somada a outros modelos identificatórios da contemporaneidade que vamos exemplificar ao longo do texto, pareceu de algum modo, reforçar a produção de estereótipos e encobrir de forma latente $\mathrm{o}$ preconceito, a discriminação, o 'autoritarismo' e ações de violência e exclusão entre os adolescentes.

Assim, era comum ouvir os adolescentes dizerem que, por exemplo, caberia ao homem prover o sustento $e$ a segurança da família, delimitar as regras da casa e demarcar seu lugar de 'chefe da casa'. Algumas propagandas financiadas por grandes empresas, têm incorporado essas ideias e proposto a valorização desse homem 'masculino', 'viril', 'compulsivo', 'racional' e 'superior', como modelo para a venda de seus produtos. A questão é que junto à compra dessas mercadorias, também é consumido e mantido o referencial simbólico do que supostamente seria esse 'ser homem'. Ou seja, para se enquadrar no modelo valorizado socialmente do que seria 'ser homem' é preciso consumir, e assim, adquirir essas características personificadas nos objetos.

Neste sentido, consumir tornou-se sinônimo de 'ser' e para 'existir' enquanto indivíduos; os adolescentes seriam, nesta lógica, encorajados a consumirem cada vez mais já que a possibilidade de autorealização, de prestígio social, de virilidade e masculinidade, de admiração pelo outro, bem como da própria felicidade, estaria ideologicamente atribuída ao mero ato de consumir.

Sobre o papel das mulheres, os adolescentes diziam que essas teriam como obrigação moral cuidar da casa e dos filhos, fazer todas as atividades domésticas e serem submissas ao marido. Várias propagandas reforçam essas ideias $e$ continuam exigindo das mulheres uma conduta moral impecável, à exemplo muito difundido nas mídias do ideal de mulher 'bela, recatada e do lar'. Essa frase foi utilizada como slogan de muitas propagandas que mobilizaram uma série de discussões nas redes sociais, mas também continuaram reforçando algumas idealizações sobre o papel da mulher na família. Gostaríamos de explorar duas delas.

A primeira idealização está bem distante da realidade das adolescentes do projeto, já que a mulher é colocada no lugar de 'senhora do lar', na qual sua submissão ao marido $e$ aos filhos é ofuscada pelo 'direito' de gozar de privilégios, decorrentes de sua condição econômica favorável. Esse modelo ganha destaque e mobiliza o desejo da maioria das mulheres do país à buscarem por uma idealização inalcançável, já que lhes falta não só os privilégios, mas todos os três atributos tão quistos em nossa sociedade: ser 'bela, recatada e do lar'. Resta-lhes, então, se identificar com o segundo modelo de mulher: 'a doméstica do lar'; que não precisa ser bela e nem ter vaidade, só é 
preciso suportar horas de trabalho duro; que não lhe é exigido ser recatada, só deve 'aceitar' os assédios tão naturalizados em nossos dias; e por fim, precisa suportar a jornada dupla de trabalho e relegar sua família e seus filhos para cuidar da família e dos filhos dos outros.

Romper com essa dura realidade talvez seja o maior desafio, já que para as adolescentes do projeto, em sua maioria, pobre e negra, não conseguem identificar nas mulheres de seu convívio esse modelo de 'senhora do lar'. E mesmo havendo esses traços de realidade que as fazem enxergar sua própria condição de mulher 'doméstica e do lar', a mídia tende a utilizar outras categorias de identificação a fim de possibilitar o 'enquadre' destas que não se encaixaram nos padrões pré-estabelecidos. Esses outros modelos referem-se, por exemplo, as lindas mulatas de periferia que compõem os comerciais de cerveja, as musas do carnaval $e$ do verão $e$ até mesmo, as empregadas domésticas das novelas e seriados que conseguiriam estar relativamente 'próximas' dessa idealização de mulher tida como 'senhora branca e rica do lar'. É claro que em outra condição, mas que em linhas gerais, daria à sensação de que essa proximidade as elevaria a esse modelo desejado.

A soma desses dois modelos de identificação 'homem e mulher', sugerem ainda um terceiro modelo que gostaríamos de discutir: o modelo de família. A configuração familiar na atualidade tem ganhado outros contornos que não mais aquele modelo nuclear, padronizado $e$ universal de família. Entre os adolescentes esse modelo poderia ser considerado falido e/ou insustentável, visto que suas famílias tinham configurações diversas e parecia não o ter como referência predominante. Entretanto, para os adolescentes esse modelo familiar tradicional é significativamente desejável, pois viver a partir deste parecia sustentar um desejo anterior: o de ser 'aceito socialmente' $e$ garantir certos 'privilégios' dele oriundos. Quais privilégios estamos falando? Daqueles que são constantemente produzidos pela indústria cultural $e$ disseminados em forma de propagandas, à exemplo, os comerciais de margarina, que reforçam uma ideia ilusória de 'família feliz', que tem uma 'boa casa', 'alimentos à vontade', 'animais de estimação' e o aconchego de todos os membros da família.

A ideia de 'família tradicional brasileira' então, possuiria os atributos necessários para se desfrutar de uma vida tranquila e prazerosa. Entretanto, como essa ideia de existência humana sem acometimentos não passa de uma ilusão conforme conjectura Freud (1930/2010), a indústria cultural usufrui dessa fantasia humana para produzir objetos que ideologicamente ganham o valor desses estereótipos desejados. Assim, é produzido nesses adolescentes a necessidade de consumir, pois a identificação com essa ideia de sempre usufruir de uma vida feliz 'consumista', passa a ser adquirida a partir da obtenção de produtos personificados, e não necessariamente por meio da figura de outro, humano.

Outro exemplo, que era bastante comum no discurso dos adolescentes refere-se a uma suposta meritocracia que 
parecia condicionar todos eles e elas a um 'fracasso existencial', já que diziam que pouco se esforçavam nas atividades em que realizavam. Na escola, por exemplo, a maioria se dizia 'repetentes' $e$ 'incapazes' de conseguirem ingressar em uma universidade pública. No trabalho não era diferente, já que para a maioria deles que ocupava cargos pouco prestigiados $e$ tinham uma remuneração baixa, a ascensão profissional era algo improvável. A escola também demonstrava dificuldades em propiciar espaços de potência $e$ desenvolvimento desses adolescentes, principalmente porque também reforçava esses discursos meritocráticos de 'esforço e empenho' e aderiam a ideias de que 'nada poderia ser feito' por esses alunos que, ou precisam trabalhar para ajudar suas famílias e "não teriam perspectiva nenhuma de suas vidas', ou então, que já haviam sido absorvidos pelo mundo do crime e do tráfico de drogas, cujo 'destino já estaria traçado'. Essas narrativas, só reforçam ainda mais o processo de discriminação $e$ exclusão social desses adolescentes, pois cumprem o papel de segregar e determinar o 'lugar social' de cada indivíduo, bem como acaba paralisando toda a potência $e$ capacidade humana de transformação de si mesmo e da realidade em que se vive. A escola, também produz e reproduz esses discursos e parece desacreditar em seu papel humanizador e emancipatório. Tal situação requer de nós atenção e também proposições emergenciais no resgate dos valores éticos e educacionais da escola no país.

Esse cenário, faz emergir três grandes questões: por que esses modelos ainda permanecem como um ideal a ser sustentado na sociedade atual? Ou ainda, por que as pessoas se deixam convencer por ideias racionalmente contraditórias $e$ inconsistentes? E por fim, como têm se dado o processo de identificação $e$ construção egóica desses adolescentes a partir desses modelos ilusórios de identificação?

A princípio supomos que esses modelos ilusórios de identificação estariam sendo sustentados por uma inversão significativa no processo de identificação $e$ constituição psíquica desses indivíduos, da qual arriscamos dizer que: para poder se identificar com esses modelos produzidos na atualidade, exige-se supostamente poder de compra.

Tal fato, estaria ocorrendo, pois na sociedade capitalista, a propaganda, sob os ditames da industrial cultural, estaria vendendo esses modelos de identificação como se fossem mercadorias a serem adquiridas e consumidas pelos indivíduos. Ou seja, os meios de comunicação por meio das propagandas e comerciais de TV, passaram a apresentar a mercadoria não só como tendo vida própria - descolada de sua função social -, como também "possuidora de um poder muito superior ao homem, como portadora da capacidade de lhe trazer a "felicidade", acabar com suas angústias e toda forma de tristeza" (CANIATO e RODRIGUES, 2012, p. 229), além de se apresentar como portadora de modelos identificatórios pré-formatados e destinados ao consumo dos indivíduos.

Essa inversão fetichista, estaria viabilizando que os adolescentes ao invés de se identificarem com os modelos 
identitários humanos, estariam se identificando com a própria mercadoria tornada elemento de identificação. Nesta lógica, as propagandas estariam produzindo uma espécie de identificação ilusória dos adolescentes com ideais padronizados da indústria cultural, como também estariam orientando suas vidas nos mesmos princípios da mercadoria. Ou seja, com a mesma fluidez, volatilidade $e$ descartabilidade.

É importante salientar, que esse processo de identificação com a mercadoria só será completo a partir do poder de compra dos indivíduos, já que os objetos de consumo não estão igualmente disponíveis para todos que desejam adquiri-los. Os próprios alunos trouxeram em suas falas que era importante vestir roupas de marca para ser visto e valorizado pelos outros, inclusive como forma de se mostrar atraente sexualmente. $\mathrm{O}$ que se observa não é a valoração do valor de uso dessas mercadorias, mas o enaltecimento do valor de troca produzido pela indústria cultural correspondente ao sistema neoliberal vigente.

Em relação ao convencimento das pessoas acerca de ideias racionalmente contraditórias, Freud (1921/2011) conjectura sobre discursos que não necessitam de uma criticidade para se sustentar dentre um considerável contingente de indivíduos (a massa). O autor destaca que essa ausência de razão se manifesta a partir de uma regressão egóica, semelhante ao funcionamento psíquico de uma criança: os objetos são segmentados entre bons e maus, o todo é fragmentado em partes e a capacidade de simbolização e abstração tornam-se limitadas.

Diante do cenário da indústria cultural, essa confusão de ideias é gerada quando, por exemplo, as características humanas como vitalidade, emoção $e$ inteligência, só são facilmente reconhecidas no indivíduo que possui poder de compra. A 'coisificação' do homem exige que ele consuma os objetos ideologicamente personificados, para que ele se 'rehumanize'.

Destarte, a indústria cultural produz e manuseia essa regressão à medida que o consumo irrestrito é ideologicamente defendido como o modo de vida inevitável para integrar-se na sociedade atual. A ideia é que você só será reconhecido, respeitado, admirado e até desejado, se for possível comprar a 'felicidade' da Coca-Cola, a 'sofisticação' da Calvin Klein, a 'elegância clássica' da Channel e a 'inteligência' e 'espontaneidade' da Free (SEVERIANO, 2010).

A terceira questão que lançamos sobre como têm se dado o processo de identificação e construção egóica desses adolescentes, a partir desses modelos ilusórios de identificação, exige de nós algumas considerações sobre o adolescer $e$ seus desdobramentos na atualidade. Deste modo, longe de apresentar uma visão determinista sobre o adolescer, propomos pensar esse período da vida a partir de um contexto pauperizado, diferentemente de leituras habitualmente consolidadas desta fase que contemplam vivências estritamente burguesas. $\mathrm{O}$ adolescente pobre, ao contrário de ter o privilégio de apenas estudar e fazer atividades esportivas 
e/ou lúdicas ao longo do dia, quando consegue se manter na escola, geralmente necessita trabalhar fora para contribuir na renda familiar, ajudar a cuidar dos irmãos e dos afazeres domésticos. Dessa maneira, a intersecção econômica transforma massivamente a subjetivação desse adolescente e exige dele responsabilidades que, a princípio, seriam exclusivas da vida adulta.

Quando o período da adolescência é desenvolvido teoricamente sem que seja evidenciado o fator socioeconômico, este é geralmente descrito como um momento marcado por intensas identificações necessárias para $\mathrm{o}$ processo de individuação. Muitos autores como Ruffino (2005), compreendem esse período como um momento da vida humana enquanto um devir em construção, com intersecções socioeconômicas, políticas, históricas e culturais. Além disso, haveria no adolescimento uma demanda simbólica voltada ao outro, cuja característica principal é da urgência identitária. Arpini (2003), complementa e aponta que é necessário pensar o olhar que o adolescente constrói de si com o modo que os outros o compreendem e o qualificam, pois ele constitui sua identidade mantendo ou transformando a expectativa social atribuída a ele.

Em consequência desse período evolutivo exigir uma intensa constituição identitária, a adesão desses adolescentes aos valores mercadológicos produzidos pela indústria cultural e disseminado pelos meios de comunicação, tende a ser intensificado. A vinculação com seus pares pode se tornar fragilizada e perder a sua capacidade de singularizar e autonomizar. Isso porque, uma vez que os discursos ideológicos têm forte poder de padronização e capturam os adolescentes em sua forma de pensar, agir e se comportar. Esses adolescentes não conseguem a plenitude no processo de constituição de sua verdadeira identidade. Enfim, a confusão identitária se estabelece também na relação entre os pares.

$\mathrm{Se}$ tratando de adolescentes pauperizados, as representações destinadas a eles quase sempre ganham uma conotação pejorativa, haja vista que há uma associação entre pobreza $e$ vadiagem/criminalidade que, segundo Coimbra (2005), está presente na nossa sociedade desde o século XIX e advém de teorias racistas e eugenistas em uma tentativa de controlar as ações dessa parcela da população.

Assim, as possibilidades dos adolescentes pauperizados se identificarem "com aspectos considerados negativos pela sociedade em geral, que fazem referência à violência, à força e etc" (Arpini, 2013, p.16), se tornam consideráveis na medida em que se encontram submetidos à essas condições de violência, discriminação $e$ exclusão. Há uma espécie de funcionamento social que conduz à adesão passiva desses adolescentes, que facilita a internalização da violência e do preconceito social.

Nesse cenário, a constituição de sua identidade e perspectiva de futuro se torna comprometida, visto que a introjeção de estigmas sociais os faz acreditar que todas as suas possibilidades de existência estariam condicionadas a tudo aquilo que lhe é rejeitado socialmente. Como por 
exemplo, a internalização de ser incapaz a partir da ideologia meritocrática, da sua inserção em uma família, em certa medida, 'fracassada' por não seguir o modelo nuclear patriarcal, bem como o sentimento de incompetência por não se enquadrar dentro dos modelos de 'ser homem ou mulher' descritos acima. Dessa maneira, esses modelos identificatórios ilusórios aos quais esses adolescentes estariam submetidos correspondem a falsas representações simbólicas de competência, já que não conseguem ter acesso aos produtos de marca ofertados pelo mercado. Esses estereótipos ilusórios, só despertam sentimentos hostis deles com eles próprios, deles com seus pares, e deles com a sociedade em geral.

A complexidade dessas questões identitárias e da violência embutida nelas, evidenciam a importância de espaços de reflexão que possibilitem a esses adolescentes desvelar esses engodos midiáticos a caminho da construção de si mesmos e do fortalecimento de vínculos de alteridade e de amparo entre eles. Uma saída a ser pensada é que esses adolescentes conscientizados de toda essa violência e hostilidade contra eles, possam se reunir em relações de solidariedade $e$ quiçá de organização política para uma possível mudança de vida. Nessa direção, o Projeto Phenix sob os preceitos de uma educação emancipatória, cunhada por Adorno (1976), se inscreve no contexto da escola junto aos adolescentes, com o intuito de incitar a potencialidade do devir transformador de cada um deles. Tentamos ajudá-los no fortalecimento de uma consciência crítica que os defenda da violência social e simbólica veiculada pela Indústria Cultural e ainda, propiciar certo acolhimento das angústias e sofrimentos apresentados por eles, frente aos modelos autoritários de identificação e subjetivação a que eles estão submetidos na contemporaneidade. Além disso, o projeto tem caminhado rumo a valorização dos vínculos humanos e ao resgate do poder político e emancipador da educação.

\section{Referências}

ADORNO, T. L. W. Educação $e$ Emancipação. Rio de Janeiro, Paz e Terra, 1976.

ADORNO, Theodor Ludwig Wiesengrund e HORKHEIMER, Max. Dialética do esclarecimento. Rio de Janeiro: Zahar, 1995.

ARPINI, D. M. Adolescência, situação de risco e violência. In: Violência e exclusão: adolescência em grupos populares. Bauru: EDUSC, 2003.

CANIATO, A. M. P. Preconceito e sua internalização subjetiva: poderosa força de exclusão social e destruição psíquica. Arquivos Brasileiros de Psicologia, Rio de Janeiro, v.60, n.2, 2008.

CANIATO, A. M. P.; RODRIGUES, S. M. Subjetividade e indústria cultural: uma leitura psicanalítica da cumplicidade dos indivíduos com a lógica da mercadoria. Psicologia em Revista, Belo Horizonte, v. 18, n. 2, p. 227-246, 2012. 
CARONE, I. Preconceito e discriminação racial. Psicologia em Revista, Belo Horinzonte, v.13, n.1, p. 41-68, 2007.

CHAUI, M. Democracia e sociedade autoritária. Goiás: Universidade Federal de Goiás, 2012. Disponível em: $<$ https://www.revistas.ufg.br/ci/article/view/2 4574/14151 >. Data de acesso: 13/11/2016.

COIMBRA, C. M. B.; NASCIMENTO, M. L. Ser jovem, ser pobre é ser perigoso". Rio de Janeiro: Universidade Federal Fluminense, 2005. Disponível em: $<$ WWW.SLAB.UFF.BR/IMAGES/AQRUIVOS/TEXTO S_STI/MARIA\%20L\%C3\%ADVIA\%20DO\%20 NASCIMENTO/TEXTO23.PDF>. Data de acesso: 25/06/2016.

FREUD, S. Psicologia das Massas e Análise do $E u$ e outros trabalhos. São Paulo: Companhia das Letras, 2011.

FREUD, S. O Mal-Estar na civilização, novas conferências introdutórias à psicanálise e outros textos. São Paulo: Companhia das Letras, 2010.

RoSA, ROSA, M. D.; DOMINGUES, E. O método na pesquisa psicanalítica de fenômenos sociais e políticos: a utilização da entrevista e da observação. Rio Grande do Sul: Psicologia \& Sociedade, v. 22, p. 180-188, 2010.

RUFFINO, R. Mundo moderno e cena juvenil. In: Anais do I Simpósio Internacional do Adolescente, 2005.
SEVERIANO, M. F. Lógica do mercado" e "lógica do desejo": reflexões críticas sobre a sociedade de consumo contemporânea a partir da escola de Frankfurt. In: Escola de Frankfurt: inquietudes da razão $e$ da emoção. SOARES, J. C. (Org.). Rio de Janeiro: EdUERJ, p.121-141, 2010.

Recebido em: 09/03/2018

Aprovado em: 10/04/2018 